\title{
Residue-Specific Solvation-Directed Thermodynamic and Kinetic Control over Peptide Self-Assembly with 1D/2D Structure Selection
}

Yiyang Lin, ${ }^{\dagger}$ Matthew Penna, ${ }^{*}$ Michael R. Thomas, ${ }^{\dagger}$ Jonathan P. Wojciechowski, ${ }^{\dagger}$ Vincent Leonardo, ${ }^{\dagger}$ Ye Wang, ${ }^{\dagger}$ E. Thomas Pashuck, ${ }^{\dagger, \S}$ Irene Yarovsky, ${ }^{*}{ }^{\ddagger}$ a

${ }^{\dagger}$ Department of Materials, Department of Bioengineering, and Institute for Biomedical Engineering, Imperial College London, Exhibition Road, London SW7 2AZ, United Kingdom

${ }^{\ddagger}$ School of Engineering, RMIT University, Melbourne, Victoria 3001, Australia

\author{
Supporting Information
}

ABSTRACT: Understanding the self-organization and structural transformations of molecular ensembles is important to explore the complexity of biological systems. Here, we illustrate the crucial role of cosolvents and solvation effects in thermodynamic and kinetic control over peptide association into ultrathin Janus nanosheets, elongated nanobelts, and amyloid-like fibrils. We gained further insight into the solvation-directed self-assembly (SDSA) by investigating residue-specific peptide solvation using molecular dynamics modeling. We proposed the preferential solvation of the aromatic and alkyl domains on the peptide backbone and protofibril surface, which results
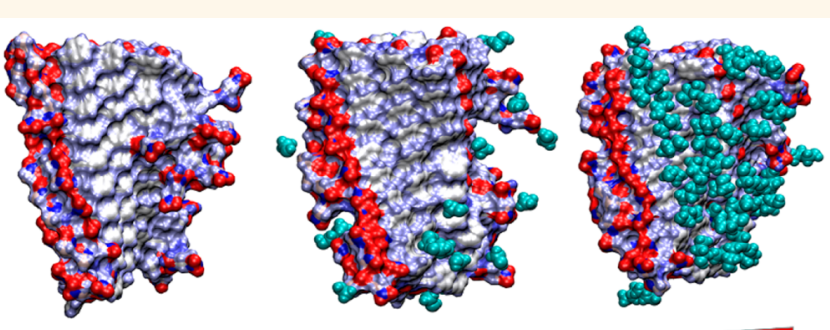

solvation-directed self-assembly in volume exclusion effects and restricts the peptide association between hydrophobic walls. We explored the SDSA phenomenon in a library of cosolvents (protic and aprotic), where less polar cosolvents were found to exert a stronger influence on the energetic balance at play during peptide propagation. By tailoring cosolvent polarity, we were able to achieve precise control of the peptide nanostructures with 1D/2D shape selection. We also illustrated the complexity of the SDSA system with pathway-dependent peptide aggregation, where two self-assembly states (i.e., thermodynamic equilibrium state and kinetically trapped state) from different sample preparation methods were obtained.

KEYWORDS: self-assembly, peptide solvation, $2 \mathrm{D}$ structures, fibrils, pathway dependence

$\mathrm{T}$ he study of biologically relevant self-assembly is essential for dissecting the molecular basis of biological events such as protein misfolding and amyloid fibrillation and also for guiding the design of biomimetic materials. ${ }^{1}$ Among these, the sequence-defined oligopeptides have attracted intense interest owing to the high versatility of self-assembled structures (1D, 2D, and 3D) and the chemical functionality that originates from the structural complexity of combinations of the 20 natural amino acids. ${ }^{2-6}$ Thermodynamically, the free energy landscape of bioensembles can be perturbed by applying biological and chemical stimuli that alter the system enthalpy (e.g., chemical bonding) and entropy (e.g., solvation effects). ${ }^{7-13}$ Through altering the molecular structures and thereby the intermolecular forces, sequencecoding peptide aggregation and hydrogelation can be rationally modulated by external stimuli including $\mathrm{pH}$, light, metal ions, and enzymes. ${ }^{14-18}$ For instance, alkaline phosphatase-catalyzed dephosphorylation of phosphorylated tyrosine residues was demonstrated to efficiently promote the hydrogelation of short peptides, enhance the supramolecular ordering at nanoscale, and regulate cancer cell fate. ${ }^{18-20}$ Biological self-assembly can be also regulated via entropic control. One example is the protein denaturation induced by urea, which interacts favorably with the peptide backbone via hydrogen bonding. This acts to shift the conformational equilibrium toward the unfolded ensemble by allowing greater solvation of hydrophobic side chains. ${ }^{21}$

Received: October 23, 2018

Accepted: January 16, 2019

Published: January 23, 2019 
The complexity of molecular self-assembly in biological systems also lies in their thermodynamic nonequilibrium features (e.g., metastable and kinetically trapped states). One example is the fibrillation of amyloid proteins, a process that is not only guided by the thermodynamic energy landscape but also modulated by the kinetics of self-assembly and multiple competing fibrillation pathways, leading to amyloid polymorphism. $^{22}$ In supramolecular systems, complex pathways can play an important role in determining the outcome of selfassembly. ${ }^{23-37}$ Pathway-driven complex self-assembly originates from a combination of different noncovalent intermolecular forces that govern molecular interactions and spontaneous aggregation, where nonequilibrium states can emerge under specific conditions. Such pathway-dependent self-assembly has become an attractive strategy to construct dynamic materials with a multitude of diverse structures. ${ }^{23-37}$

Biologically, the influence of the solvation effect on biomolecules has a strong impact on the energetics and kinetics of chemical processes in solution including protein folding, micellization, enzyme-substrate recognition, and the formation/stability of lipid membranes. ${ }^{38,39}$ In particular, the interaction of protein molecules with water and the involvement of water molecules in protein conformational change and enzymatic reaction have been extensively explored. The changes in excluded volume and contact interaction with the surface of a protein have been suggested as the mechanisms responsible for the changes in cosolvent-induced protein stability. Moreover, solvation has been reported to play a decisive role in guiding the self-assembly of polymers and amphiphilic peptides. ${ }^{40-44}$ For example, trace amounts of solvents were reported to modulate dipeptide (Phe-Phe) selfassembly in dichloromethane, in which solvent-bridged hydrogen bonding is demonstrated as a crucial force in directing fiber formation. ${ }^{43}$

In this work, we report the phenomenon of solvationdirected self-assembly (SDSA) and its ability to precisely control peptide propagation with $1 \mathrm{D} / 2 \mathrm{D}$ selectivity and systematically examine the solvation effect with a library of cosolvents (protic and aprotic) both experimentally and computationally. We applied molecular dynamics (MD) to investigate the interactions beween cosolvents and key amino acid segments of the peptide and hydrophobic protofibril surfaces, through which we highlight the essential roles of the cosolvent polarity in mediating peptide solvation and selfassembly. We further observed pathway-dependent peptide self-assembly in the SDSA system, where distinct supramolecular products with $1 \mathrm{D} / 2 \mathrm{D}$ structure selection were obtained from different sample preparation methods. We believe that the study of solvation effects in this work can provide a better understanding of biomolecule-solvent interactions and a strategy to thermodynamically and kinetically control the self-assembly of biological molecules of varied structure and function.

\section{RESULTS AND DISCUSSION}

We synthesized an asymmetric peptide amphiphile (F6C11) containing a hexaphenylalanine (Phe ${ }_{6}$ ), a hydrocarbon tail (C11), and glutamic acids (Glu), which self-assembles into Janus single-layer nanosheets with $\sim 5 \mathrm{~nm}$ thickness (Figure 1) as we recently reported. ${ }^{45}$ The design was such that the aromatic stacking in the $y$-axial and $\mathrm{H}$-bonding in the $x$-axial direction directed peptide association in both directions. The crucial role of aromaticity of phenylalanine was highlighted by

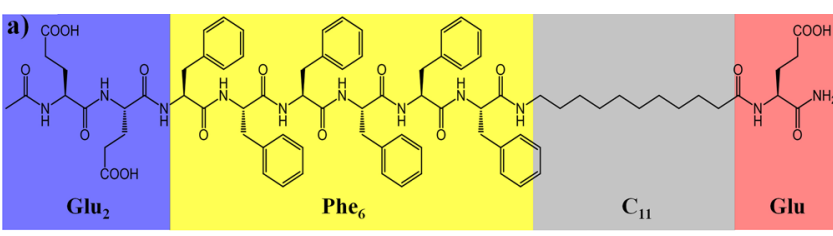

b) solvation-directed self-assembly (SDSA)

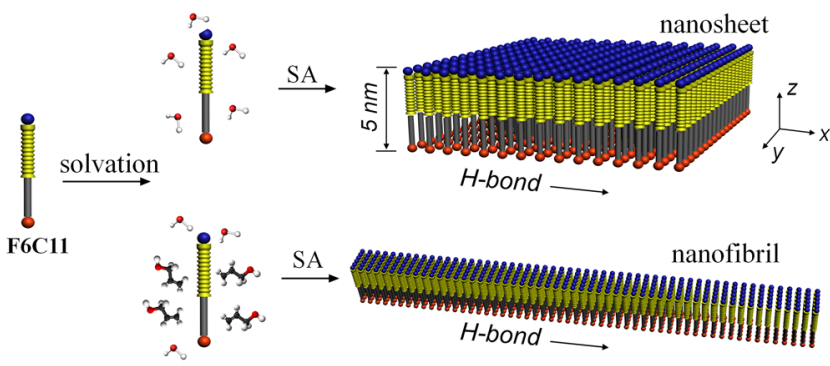

$\because \mathrm{H}_{2} \mathrm{O}$-propanol

Figure 1. (a) Asymmetric peptide (F6C11) containing one glutamic acid (Glu) at the C-terminus, two glutamic acids ( $\mathrm{Glu}_{2}$ ) at the N-terminus, six phenylalanine residues ( $\mathrm{Phe}_{6}$ ), and a hydrocarbon chain (C11). (b) Schematic of solvation-directed selfassembly with $1 \mathrm{D}$ and $2 \mathrm{D}$ shape selectivity: formation of $2 \mathrm{D}$ nanosheets in aqueous solution is proposed to be guided by hydrogen bonding in the $x$-axial direction, $\pi-\pi$ stacking in the $y$ axial direction, and hydrophobic effect in both directions. Amyloid-like fibrils are the thermodynamically favored products in the presence of cosolvents (i.e., $n$-propanol), where the strong solvation effect of aromatic and alkyl groups by $n$-propanol are supposed to weaken the $\pi-\pi$ stacking and hydrophobic effect.

the self-assembly of a mutated peptide where phenylalanine was replaced by 3-cyclohexyl-L-alanine. As shown in Figure S1, the mutated peptide aggregates into nanobelts with smaller diameters. The presence of hydrophobic interactions between C11 alkyl chains also contributes to peptide propagation in both directions. ${ }^{46,47}$ Collectively, a thermodynamic energy balance defined by contributions from H-bonding, $\pi-\pi$ stacking, and the hydrophobic effect resulted in the formation of Janus nanosheets. Such energetic balance can be perturbed by adjusting molecular interactions via modification of the peptide sequences. For example, helical nanofibrils became energetically favored when the strength of $\pi-\pi$ stacking in the $y$-axial direction was weakened by reducing the number of phenylalanine residues (i.e., $\mathrm{Phe}_{5}, \mathrm{Phe}_{4}$, and $\mathrm{Val}_{6}$ ). ${ }^{45}$ Here, we hypothesized that the intermolecular forces, especially the aromatic stacking (Figure $1 \mathrm{~b}$ ), could also be modulated by introducing a cosolvent to adjust the peptide-solvent interactions without having to change the chemistry of peptide structures.

To test our hypothesis, we added methanol as a cosolvent to the growth solution of F6C11 and studied the morphological changes of peptide nanostructures. As shown in Figure 2a,b, the length $(L)$ of the nanosheets increased from $1.41 \pm 0.14$ to $2.37 \pm 0.28 \mu \mathrm{m}$ with methanol concentration increasing from 0 to $5 \%$. The elongation of the $2 \mathrm{D}$ nanosheets continued upon increasing the methanol concentration to $10 \%$, generating nanobelts of $6.74 \pm 1.30 \mu \mathrm{m}$ in length (Figure 2c). Interestingly, when the methanol content reached $15 \%$, amyloid-like nanofibrils with a diameter $(D)$ of $\sim 11 \mathrm{~nm}$ became the dominant products (Figure $2 \mathrm{~d}$ ). We propose that peptide molecules can propagate in two dimensions driven by the intermolecular forces in the $x$ - and $y$-axial directions 
Increasing methanol concentration
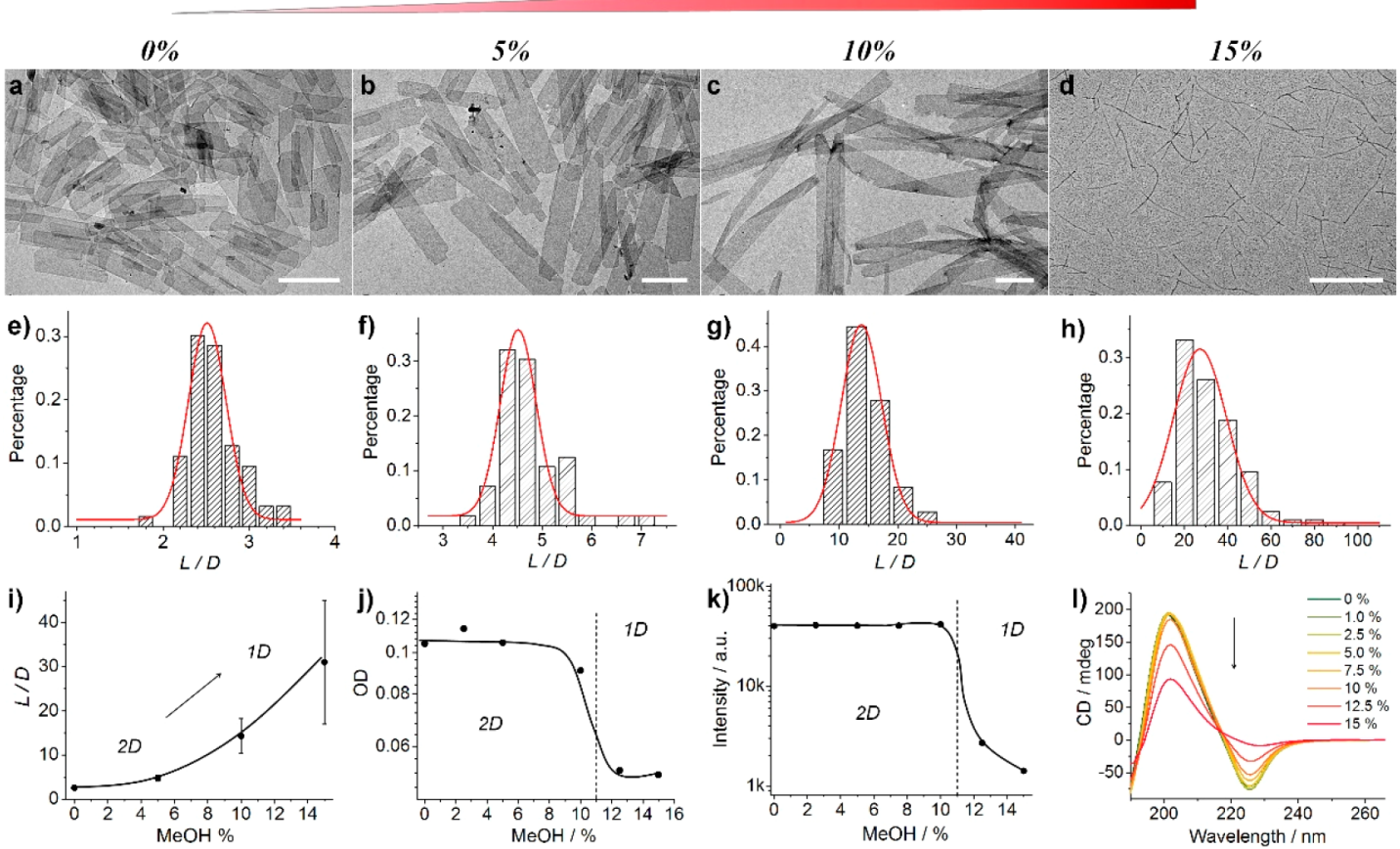

Figure 2. (a-d) Transmission electron microscopy (TEM) images and (e-h) histogram profile of length/diameter ratio $(L / D)$ of F6C11 $(0.25 \mathrm{mM})$ supramolecular structures with increasing methanol concentrations: $(\mathrm{a}, \mathrm{e}) 0 \%$; $(\mathrm{b}, \mathrm{f}) 5 \%$; $(\mathrm{c}, \mathrm{g}) 10 \%$; $(\mathrm{d}, \mathrm{h}) 15 \%$ methanol. The nanosheet-to-nanofibril (2D-to-1D) structural evolution occurs with an increase in methanol concentration. (i) $L / D$ ratio of peptide nanostructures determined from TEM images (mean \pm SD). ( $j$ ) Optical density (OD) and (k) ThT fluorescence intensity of peptide solution. (1) Circular dichroism (CD) spectra showing the disordering of $\beta$-sheet secondary structures with increased methanol. Scale bar: $(\mathrm{a}-\mathrm{c}) 1 \mu \mathrm{m}$ and $(\mathrm{d}) 500 \mathrm{~nm}$.
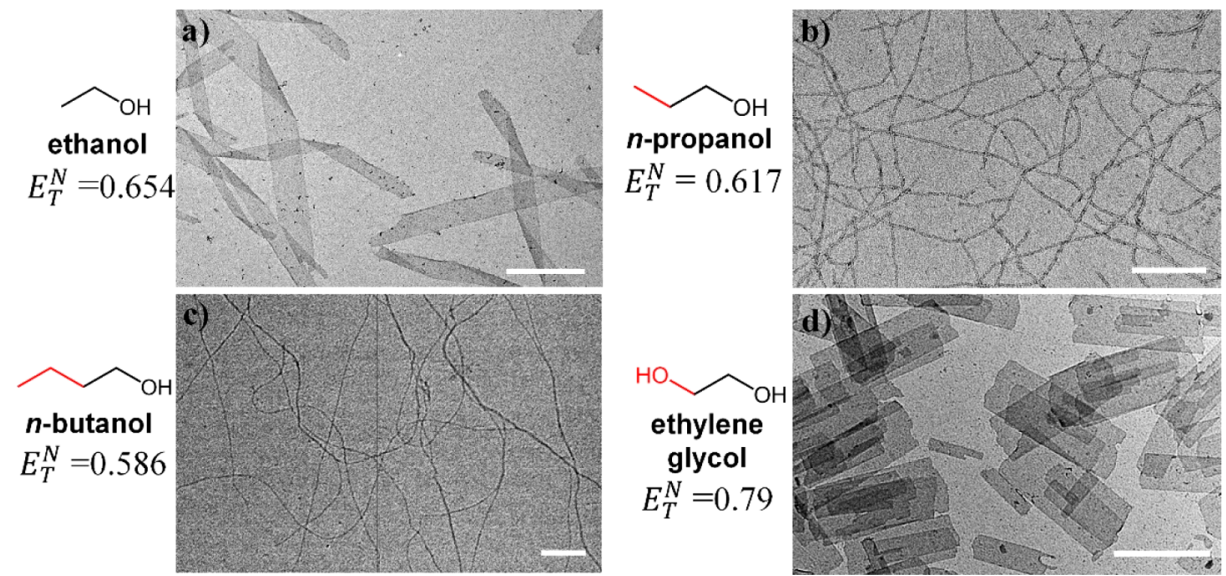

Figure 3. TEM images showing the morphological changes of F6C11 self-assembly $(0.25 \mathrm{mM})$ in the presence of different alcohols $(5 \%)$ : (a) ethanol, (b) n-propanol, (c) $n$-butanol, (d) ethylene glycol. Peptide nanofibrils were the thermodynamically favored morphology in the presence of less polar cosolvents like $n$-butanol and $n$-propanol, whereas nanosheets were the dominant morphology when the cosolvent is more polar (e.g., ethylene glycol). A cosolvent with intermediate polarity (e.g., ethanol) drives F6C11 self-assembly into elongated nanobelts. Scale bar: (a,d) $1 \mu \mathrm{m}$; (b,c) $200 \mathrm{~nm}$.

(Figure 1). As the methanol content increases, peptide assembly in the $y$-axial direction is less favored (discussed later), and as a result, more peptide monomers will propagate in the $x$-axial direction, which increases the length of peptide nanostructures. The morphological changes were also seen in the length/diameter ratio $(L / D)$ of peptide nanostructures (Figure $2 \mathrm{e}-\mathrm{h}$ ), which increased from $2.6,4.8,14$, to 31 as methanol concentration increased from $0,5,10$, to $15 \%$. Such changes were confirmed by structure illumination microscopy (SIM) imaging stained with a hydrophobic dye (Nile red,
Figure S2). Meanwhile, the decrease in optical density (OD) of the peptide solution (Figure $2 \mathrm{j}$ ) confirms the nanosheet-tonanofibril transition with the addition of methanol. We also employed Thioflavin T (ThT, Figure $2 \mathrm{k}$ ) assay to probe the strength of peptide-peptide stacking. We noted that ThT fluorescence decreased as the methanol concentration is greater than $12.5 \%$, suggesting that the rigid peptide stacking becomes less ordered, in agreement with the 2D-to-1D morphological transition. Circular dichroism (CD, Figure 2i) spectra of the nanosheets are indicative of the existence of $\beta$ - 
sheets with a positive peak at $201 \mathrm{~nm}$ and a negative peak at $225 \mathrm{~nm}$, both of which were red-shifted from typical $\beta$-sheet peaks of 196 and $218 \mathrm{~nm}$, respectively. This is known to be due to the aromatic interactions between phenylalanine groups that act to distort the $\beta$-sheets. ${ }^{48-50}$ Increasing the methanol content resulted in the gradual decrease in CD signals, showing again that the ordered peptide stacking was weakened. Notably, the preformed nanofibrils can transform into nanosheets when the methanol was removed from the system via solvent exchange (Figure S3).

We further investigated the effect of other alcohols on SDSA with ethylene glycol, ethanol, $n$-propanol, and $n$-butanol, which have the relative polarity $\left(E_{T}^{N}\right)$ of $0.79,0.654,0.617$, and 0.586 , respectively. ${ }^{51}$ Unlike methanol, the presence of $5 \%$ ethanol in the peptide growth solution led to the formation of elongated nanobelts (Figure 3a), whereas nanofibrils formed with high concentrations of ethanol (10-15\%, Figure S2). For the less polar $n$-propanol and $n$-butanol, amyloid-like fibrils become the preferred morphologies when $5 \%$ cosolvents are present (Figure 3b,c). In the case of polar ethylene glycol, nanosheets were the favored morphology in the presence of 5\% cosolvent (Figure $3 \mathrm{~d}$ ). These results indicate that SDSA is also dependent on the cosolvent polarity, where less polar cosolvents (e.g., $n$-propanol and $n$-butanol) can induce the nanosheet-to-nanofibril transition more efficiently than polar cosolvents do (e.g., ethylene glycol, methanol, and ethanol). We further examined the CD spectra of the peptide solution to compare the effect of cosolvent polarity on the peptide arrangements (Figures S5 and S6). In comparison with methanol, the presence of ethanol and $n$-propanol weakened the strength of $\mathrm{F} 6 \mathrm{C} 11 \beta$-sheet structures in a more efficient manner, as can be seen from the decreased CD intensity at 201 and $225 \mathrm{~nm}$. Interestingly, further addition of cosolvents above a threshold concentration $(7.5 \%$ of ethanol or $5 \%$ of $n$ propanol) caused a CD spectral distortion away from the $\beta$ sheet. The interpretation of the CD spectra at high cosolvent contents is still unclear at this stage. However, from the combined results of transmission electron microscopy (TEM) and $\mathrm{CD}$, we have come to the conclusion that cosolvents with a lower polarity (e.g., $n$-butanol and $n$-propanol) are more efficient in causing 2D-to-1D structural transformation of peptide self-assembly. Moreover, the cosolvent-induced peptide fibrils remain single-layer structures $(2-3 \mathrm{~nm})$, as indicated from the atomic force microscopy (AFM, Figure S7). This thickness is less than that of peptide nanosheets, which is probably because the peptide solvation induced by cosolvents unfavored the extended peptide conformation.

We further explored the alcohol-peptide interactions by molecular dynamics (Figure S8) simulation to reveal the role of the cosolvents (i.e., methanol, ethanol, $n$-propanol, and $n$ butanol) in determining peptide self-assembly. Figures $S 9$ and S10 present the behavior of individual F6C11 molecules in the solvent mixture ( $5 \%$ cosolvent), showing the radial distribution function (RDF) between the alcohol (oxygen and terminal carbon) and peptide molecules. All alcohol molecules showed affinities toward the alkyl tail (C11) and hexaphenylalanine group $\left(\mathrm{Phe}_{6}\right)$ higher than those of the terminal glutamic acid (Figures S9 and S10). It can also be seen from the higher and broader RDF peaks that the association of the less polar solvents (e.g., $n$-propanol and $n$-butanol) with the hydrophobic groups ( $\mathrm{C} 11$ alkyl and $\mathrm{Phe}_{6}$ ) relative to bulk concentration was stronger than polar cosolvents (e.g., methanol and ethanol). We assessed the distributions of the fraction of solvent- accessible surface area (SASA) of the six phenylalanine ( $\mathrm{Phe}_{6}$ ) residues covered by methanol, ethanol, $n$-propanol and $n$ butanol (Figure $4 a-d$ ), where the average available SASA of
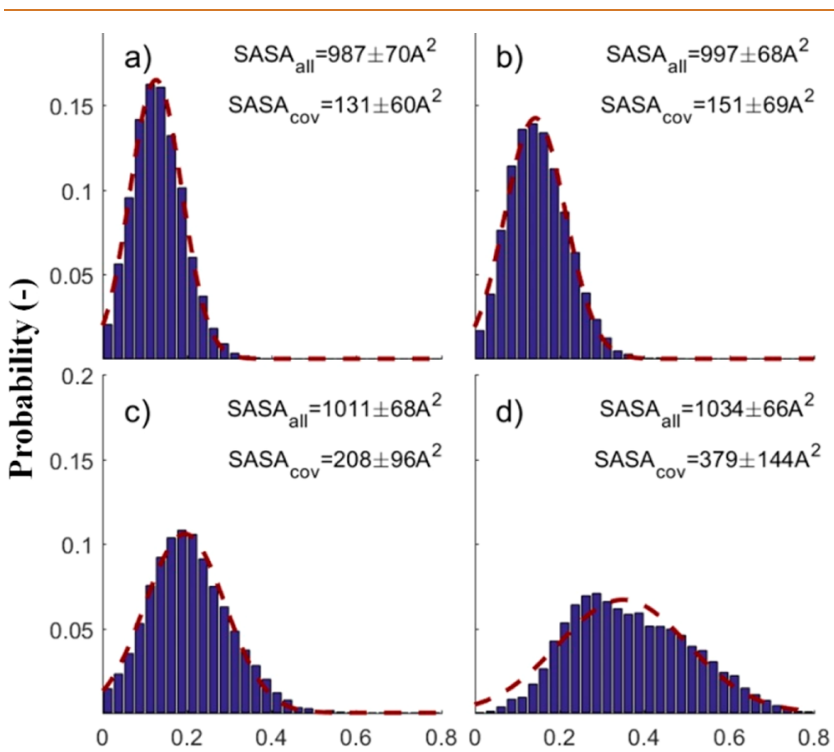

Fraction of Phe ${ }_{6}$ SASA covered by organic solvent (-)

\begin{tabular}{ccccc}
\hline \multirow{2}{*}{$\begin{array}{c}\text { F6C11 } \\
\text { Region }\end{array}$} & \multicolumn{4}{c}{ Mean Organic Solvent Coverage (\%) } \\
\cline { 2 - 5 } & Methanol & Ethanol & n-Propanol & n-Butanol \\
\hline Glu $_{2}$ & 9.8 & 9.0 & 9.6 & 11.7 \\
Phe $_{6}$ & 13.2 & 15.1 & 20.6 & 36.8 \\
C11 & 14.8 & 18.7 & 27.1 & 55.4 \\
Glu & 9.5 & 9.5 & 11.4 & 16.6 \\
Total & 12.2 & 13.4 & 17.7 & 30.9 \\
\hline
\end{tabular}

Figure 4. Distributions of the fraction solvent-accessible surface area (SASA) of the six phenylalanine $\left(\mathrm{Phe}_{6}\right)$ residues in individual F6C11 molecules covered by (a) methanol, (b) ethanol, (c) $n$ propanol, and (d) $n$-butanol. The average SASA of the $\mathrm{Phe}_{6}$ region is $\sim 1000 \AA^{2}$, and on average, 131, 151, 208, $379 \AA^{2}$ of the Phe surface is covered by methanol, ethanol, $n$-propanol, and $n$ butanol, respectively. (e) Average percentage of SASA covered by organic solvents for F6C11 molecules immersed in water-alcohol mixtures. $\mathrm{Glu}_{2}$ : two glutamic acid at the $\mathrm{N}$-terminus; $\mathrm{Phe}_{6}$ : phenylalanine; C11: alkyl group; Glu: glutamic acid at the Cterminus. Note: numbers in (e) are slightly different by $\pm 0.2 \%$ from those in $(a-d)$ due to rounding in figures $(a-d)$.

the $\mathrm{Phe}_{6}$ region was $\sim 1000 \AA^{2}$. The simulations suggest that, on average, $131,151,208$, and $379 \AA^{2}$ of the $\mathrm{Phe}_{6}$ surface is covered by methanol, ethanol, $n$-propanol, and $n$-butanol, respectively. Similarly, the SASA of the C11 alkyl tail in F6C11 peptide covered by methanol, ethanol, $n$-propanol, and $n$ butanol was calculated to be 148,187, 271, and $554 \AA^{2}$, respectively (Figures $4 \mathrm{e}$ and $\mathrm{S} 11$ ). The surface coverage was found to increase with decreasing solvent polarity (e.g., $n$ propanol and $n$-butanol). It was also noted that the surfacebound solvent molecules on charged amino acids (i.e., $\mathrm{Glu}_{2}$ and Glu) were less than those around hydrophobic $\mathrm{Phe}_{6}$ and an alkyl tail (Figures S12 and S13).

The aggregation of $\mathrm{F} 6 \mathrm{C} 11$ into a protofibril resulted in the formation of a hydrophobic wall along the sides of the protofibril due to the presence of hydrophobic phenylalanine side chains (Figures 5a and S14). This hydrophobicity did not translate to the ends of the protofibril where the backbone of the F6C11 molecules was exposed. The hydrophobic wall 

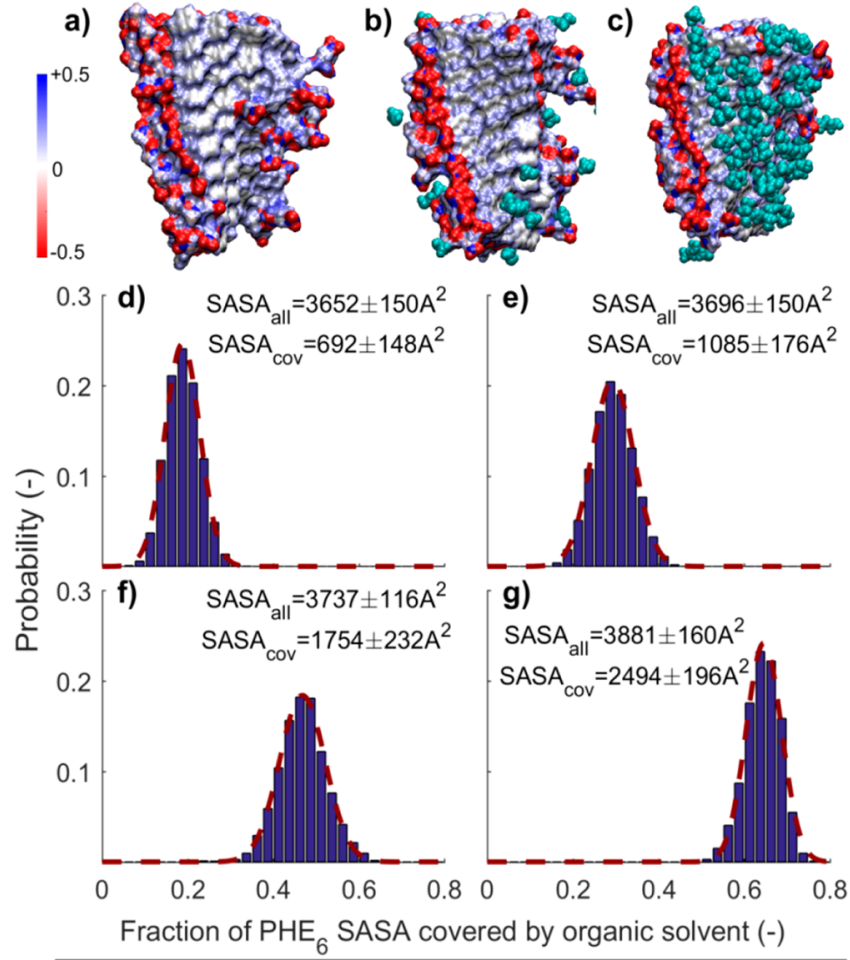

\begin{tabular}{ccccc}
\hline \multirow{2}{*}{ h6C11 Region } & \multicolumn{4}{c}{ Mean Organic Solvent Coverage (\%) } \\
\cline { 2 - 5 } & Methanol & Ethanol & n-Propanol & n-Butanol \\
\hline Glu $_{2}$ & 7.9 & 7.3 & 8.0 & 11.2 \\
Phe $_{6}$ & 18.9 & 29.4 & 46.9 & 64.2 \\
C $_{11}$ & 18.5 & 28.7 & 48.3 & 67.7 \\
Glu & 10.0 & 11.3 & 15.4 & 19.4 \\
Total & 14.0 & 19.2 & 30.3 & 41.2 \\
\hline
\end{tabular}

Figure 5. (a) $\mathrm{F} 6 \mathrm{C} 11_{10}$ protofibril shown as a surface with atoms colored according to charge with a color range of -0.5 (red), 0.0 (white) and +0.5 (blue). Exemplar snapshot of the F6C11 10 protofibril immersed in (b) water-methanol and (c) waterpropanol mixture. Organic solvent molecules within $4 \AA$ of the F6C $11_{10}$ are shown in cyan. $(\mathrm{d}-\mathrm{g})$ Distributions of the fraction solvent-accessible surface area (SASA) of the $\mathrm{Phe}_{6}$ residues in the protofibril covered by (d) methanol, (e) ethanol, (f) $n$-propanol, and (g) $n$-butanol with fitted normal distributions. (h) Average percentage of SASA covered by organic solvents. Glu G $_{2}$ two glutamic acid at the N-terminus; Phe $_{6}$ : phenylalanine; C11: alkyl group; Glu: glutamic acid at the $\mathrm{C}$-terminus.

appeared to act as a small surface prone to association with nonpolar components of the cosolvent. Figure 5b,c shows example snapshots of the $\mathrm{F} 6 \mathrm{C} 11_{10}$ protofibril along with the methanol and propanol present within $4 \AA$ of the protofibril. Distributions for the fraction of the $\mathrm{Phe}_{6}$ region covered by the alcohols are shown in Figure $5 \mathrm{~d}-\mathrm{g}$. There was a dramatic increase in coverage from 18.9 and $29.4 \%$ for methanol and ethanol, respectively, to 46.9 and $64.2 \%$ for $n$-propanol and $n$ butanol, respectively. Identical trends were observed for the coverage of the C11 alkyl chain region (Figures $5 \mathrm{~h}$ and S15), where $18.5,28.7,48.3$, and $67.7 \%$ coverage was found for methanol, ethanol, $n$-propanol, and $n$-butanol, respectively. In contrast, the SASA coverage translates to the ends of the protofibril where the backbone of hydrophilic $\mathrm{Glu}_{2}(\mathrm{~N}$ terminus) and Glu (C-terminus) ends of F6C11 was substantially less impacted by solvent polarity (Figure $5 \mathrm{~h}$ and Figures S16 and S17).
We propose that the association of peptide monomers or protofibrils into nanosheets is limited due to the volume exclusion effects associated with the interaction between less polar solvents and the hydrophobic wall of the peptides and the associated protofibrils, preventing the $\beta$-sheet stacking in the $y$-axial direction (Figure 1). We observed nanosheet formation in the presence of more polar cosolvents as the aforementioned volume exclusion effects were more limited and the association of these hydrophobic walls was subsequently possible. The large entropy cost associated with the $1 \mathrm{D}$-to-2D structural transition was likely compensated by the dewetting of the hydrophobic walls of the protofibrils, a driving force that was not present in more nonpolar cosolvents. This agrees with our previous finding that nanofibrils were the dominant product when the aromatic interaction and hydrophobic effect were weakened by removing phenylalanine and alkyl chains.

We further tested the effect of other protic cosolvents (Table 1 ), where less polar cosolvents (e.g., isobutyl alcohol, $t$-butyl

Table 1. Relationship between the Cosolvent Relative Polarity $\left(E_{T}^{N}\right),{ }^{51}$ Dielectric Constant $(\varepsilon),{ }^{52}$ and the Performance of Cosolvent-Induced Peptide Self-Assemblies (5\% cosolvent)

\begin{tabular}{rllll} 
entry & \multicolumn{1}{c}{ solvent } & $E_{T}^{N}$ & $\varepsilon$ & morphology \\
1 & 1,4-dioxane & 0.164 & 2.2 & nanofibril \\
2 & tetrahydrofuran & 0.207 & 7.58 & nanofibril \\
3 & 2-butanone & 0.327 & 18.5 & nanofibril \\
4 & $N$-methyl-2-pyrrolidone & 0.355 & 32 & nanofibril \\
5 & acetone & 0.355 & 20.7 & nanofibril \\
6 & $N, N$-dimethylacetamide & 0.377 & 37.8 & nanofibril \\
7 & $N$,N-dimethylformamide & 0.386 & 36.7 & nanofibril \\
8 & t-butyl alcohol & 0.389 & 17.7 & nanofibril \\
9 & dimethyl sulfoxide & 0.444 & 46.7 & nanofibril \\
10 & acetonitrile & 0.460 & 37.5 & nanofibril \\
11 & isopropyl alcohol & 0.546 & 18 & nanofibril \\
12 & isobutyl alcohol & 0.552 & 15.8 & nanofibril \\
13 & $n$-butanol & 0.586 & 17.7 & nanofibril \\
14 & $n$-propanol & 0.617 & 20.1 & nanofibril \\
15 & ethanol & 0.654 & 24.3 & nanobelt \\
16 & N-methyl formamide & 0.722 & 170 & nanosheet \\
17 & propane-1,3-diol & 0.747 & 35 & nanosheet \\
18 & methanol & 0.762 & 32.6 & nanosheet \\
19 & formamide & 0.775 & 109 & nanosheet \\
20 & ethylene glycol & 0.79 & 37 & nanosheet \\
21 & glycerol & 0.812 & 42.5 & nanosheet \\
22 & water & 1.000 & 80.4 & nanosheet \\
\hline
\end{tabular}

alcohol, and isopropyl alcohol) favor the formation of nanofibrils at a $5 \%$ cosolvent concentration (Figure S18). In contrast, protic cosolvents with two or more hydroxyl groups (e.g., ethylene glycol and propane-1,3-diol) do not induce peptide fibrillation when the cosolvent concentration is below $15 \%$ (Figure $S 19 \mathrm{a}-\mathrm{d})$. Due to the high polarity $\left(E_{T}^{N}=0.812\right)$, glycerol did not affect the 2D morphology of F6C11 selfassembly (Figure S19e,f). This agrees with the previous finding that glycerol stabilized amyloid oligomerization and retarded fibrillar aggregation via enhanced hydration. ${ }^{39}$

Furthermore, we screened a library of aprotic cosolvents and investigated their effects on solvation-induced self-assembly (Table 1). Interestingly, precise control over $1 \mathrm{D} / 2 \mathrm{D}$ peptide self-assembly was achieved by subtle changes in molecular 


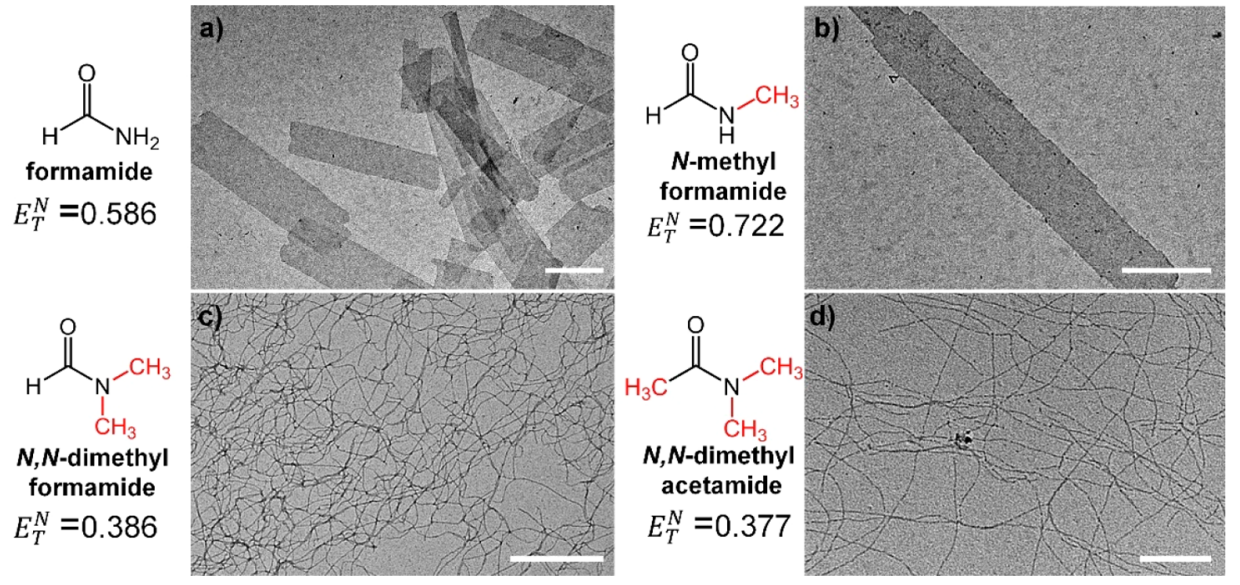

Figure 6. TEM images showing the structural evolution of F6C11 $(0.25 \mathrm{mM})$ self-assembly in the presence of aprotic solvents (5 v/v\%): (a) formamide, (b) $\mathrm{N}$-methyl formamide, (c) $\mathrm{N}, \mathrm{N}$-dimethylformamide, (d) $\mathrm{N}, \mathrm{N}$-dimethylacetamide. Noteworthy, the decrease of polarity from formamide $\left(E_{T}^{N}=0.775\right), N$-methyl formamide $\left(E_{T}^{N}=0.722\right), N, N$-dimethylformamide $\left(E_{T}^{N}=0.386\right)$, and $N, N$-dimethylacetamide $\left(E_{T}^{N}=\right.$ $0.377)$ leads to a structural transition from nanosheets to elongated nanobelts and nanofibrils. Scale bar: $(\mathrm{a}-\mathrm{c}) 500 \mathrm{~nm},(\mathrm{~d}) 250 \mathrm{~nm}$.
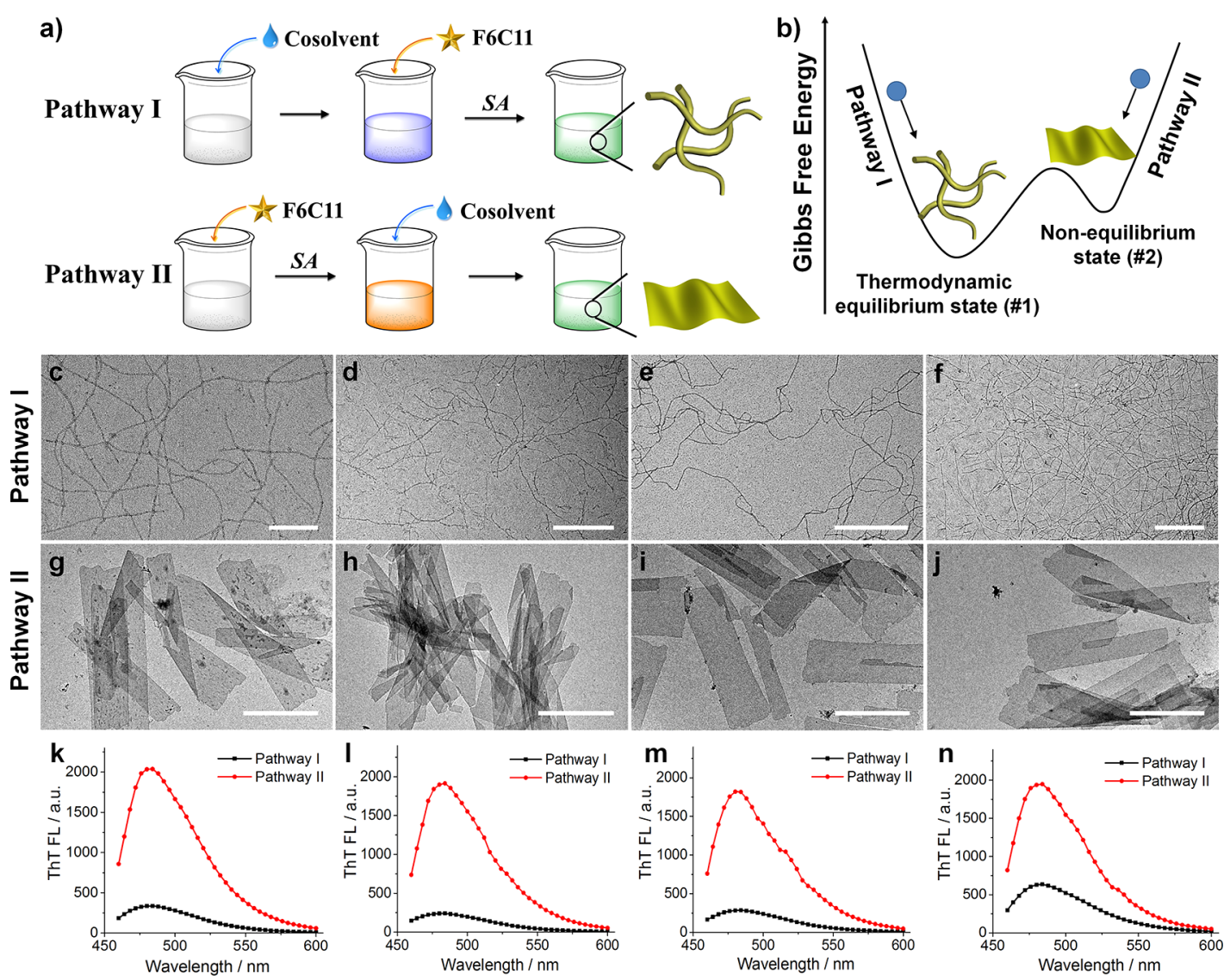

Figure 7. (a) Schematic Gibbs free energy landscape of solvation-directed self-assembly, where Pathway I led to a thermodynamic equilibrium state corresponding to the formation of fibrils (state 1), and Pathway II resulted in a kinetically trapped state corresponding to nanosheets (state 2). Pathway I: aggregation of F6C11 monomers was completed in aqueous solution containing cosolvents. Pathway II: cosolvents were added to preformed F6C11 nanosheets. (c-h) TEM images showing the amyloid-like fibrils in state 1, following Pathway I $(\mathrm{c}-\mathrm{f})$, and nanosheets in state 2, following Pathway II $(\mathrm{g}-\mathrm{j})$. Cosolvents were used to induce structural evolution of F6C11 under two pathways: (c,g) n-propanol; (d,h) isopropyl alcohol; (e,i) DMF; (f,j) THF. Scale bar: (a) $200 \mathrm{~nm}$; (d-f) $500 \mathrm{~nm}$; $(\mathrm{g}-\mathrm{j}) 1 \mu \mathrm{m}$. $(\mathrm{k}-\mathrm{n}) \mathrm{ThT}$ fluorescence in the F6C11 peptide solution showing the strengths of molecular packing varied in different SDSA pathways: (k) $n$-propanol; (l) isopropyl alcohol; (m) DMF; (n) THF.

structures of cosolvents. For example, formamide and $\mathrm{N}$ methyl formamide, which are relatively polar with an $E_{T}^{N}$ of 0.775 and 0.722 , respectively, favored the formation of nanosheets and elongated nanobelts at a concentration of $5 \%$ cosolvent (Figure 6a,b). In contrast, the less polar $N, N$ dimethylformamide (DMF, $\left.E_{T}^{N}=0.386\right)$ that has two additional $-\mathrm{CH}_{3}$ groups on the nitrogen $(\mathrm{N})$ atom led to the formation of nanofibrils (Figure 6c). This was the same for 
$N, N$-dimethylacetamide $\left(E_{T}^{N}=0.377\right)$, which has two $-\mathrm{CH}_{3}$ groups on the nitrogen atom and one $-\mathrm{CH}_{3}$ on carbonyl group (Figure 6d).

Moreover, we have observed that only those cosolvents with $E_{T}^{N}$ lower than 0.62 can thermodynamically promote peptide fibrillation (Figure S20), including acetonitrile $\left(E_{T}^{N}=0.460\right)$, dimethyl sulfoxide $\left(E_{T}^{N}=0.444\right)$, acetone $\left(E_{T}^{N}=0.355\right), N$ methyl-2-pyrrolidone $\left(E_{T}^{N}=0.355\right), 2$-butanone $\left(E_{T}^{N}=0.327\right)$, tetrahydrofuran $\left(E_{T}^{N}=0.207\right)$, and 1,4-dioxane $\left(E_{T}^{N}=0.164\right)$. Here, the cosolvents were grouped into two categories: the strong inducing solvent with $E_{T}^{N}$ of $\sim 0.164-0.654$ and the weak inducing solvent with high polarity $E_{T}^{N}$ of $\sim 0.713-1$. As suggested by $\mathrm{MD}$ simulations, less polar solvents had a larger surface coverage on the $\mathrm{Phe}_{6}$ segment and the C11 hydrocarbon chains, competing with the peptide solvation effect in water and weakening the peptide propagation in the direction perpendicular to H-bonding, which energetically favored 1D peptide self-assembly.

We noticed that the solvent-induced self-assembly can be also explained by dielectric constant $(\varepsilon)$. For example, the solvents with a high dielectric constant such as $N$-methyl formamide $(\varepsilon=170)$, propane-1,3-diol $(\varepsilon=35)$, methanol ( $\varepsilon$ $=32.6)$, formamide $(\varepsilon=109)$, ethylene glycol $(\varepsilon=37)$, and glycerol $(\varepsilon=42.5)$ were not able to induce peptide fibrillation, whereas cosolvents with lower dielectric constants favored the formation of peptide fibrils. There are exceptions such as $N, N$ dimethylacetamide $(\varepsilon=37.8), N, N$-dimethylformamide $(\varepsilon=$ $36.7)$, acetonitrile $(\varepsilon=37.5)$, and dimethyl sulfoxide $(\varepsilon=$ $46.7)$, which are more polar than methanol $(\varepsilon=32.6)$ or propane-1,3-diol $(\varepsilon=35)$ but still trigger peptide fibrillation. In this sense, compared to the dielectric constant, the relative polarity $\left(E_{T}^{N}\right)$ is believed to better correlate with the SDSA because $E_{T}^{N}$ is a parameter directly determined by the solvatochromic effect or solvent-solute interaction. On the other hand, solvation of charged headgroups ( $\mathrm{Glu}_{2}$ and $\mathrm{Glu}$ ) by organic cosolvents is less profound (Figure 5) as water plays a dominating role in solvating the ionic amino acids.

Recent work has shown that the degree of complexity in supramolecular systems is dependent on the specific selfassembly pathway. ${ }^{23,24,26,29,32-36,53}$ For example, a peptide amphiphile can self-assemble into different supramolecular morphologies depending on the sample preparation pathway, either into long filaments containing $\beta$-sheets or smaller aggregates containing peptide segments in random coil conformations. $^{24}$ In the system of $\mathrm{F} 6 \mathrm{C} 11$, the self-assembly of SDSA is pathway-dependent, where the method of sample preparation affected the supramolecular products. As shown in Figure $7 \mathrm{a}$, we used two sample preparation methods to guide peptide self-assembly in the presence of cosolvents. Following Pathway I, we directly added the peptide F6C11 to the buffered growth solution containing the desired amount of cosolvents and observed a thermodynamic equilibrium state (\#1) of the amyloid-like fibrils (Figure 7) as shown in the section above. The formation of thermodynamically stable 1D peptide fibrils is ascribed to the selective solvation of alkyl and aromatic groups by cosolvents, which prevents the $\beta$-strand stacking in the direction perpendicular to the $\beta$-sheet. Following Pathway II, we added the same amount of cosolvents to the preformed F6C11 nanosheets, generating a kinetically trapped state (\#2). In the nonequilibrilium state, nanosheets were the dominant morphology (Figure $7 \mathrm{~g}-\mathrm{j}$ ). The nanosheets prepared following Pathway II did not disassemble or transform into nanofibrils over an observable time frame ( $>2$ months). Even though the peptide systems in states 1 and 2 contained the same amount of F6C11 and cosolvent content, we observed significant differences in the morphologies of the self-assembled structures. Moreover, these two self-assembly pathways also caused significant differences in peptide-peptide association at molecular level, where strong $\beta$-sheet structures were retained in state 2 , as shown from ThT fluorescence (Figure $7 \mathrm{k}-\mathrm{n}$ ). We propose that once the F6C11 are well-packed into nanosheets through the synergistic forces of H-bonding, hydrophobic effect and aromatic stacking, the access of cosolvents to the hydrophobic face of peptide backbones is restricted and therefore the $2 \mathrm{D}$ structures will be in a nonequilibrium but kinetically trapped state (\#2). Following Pathway I, however, a strong solvation effect or solvent-peptide contact results in the formation of thermodynamically stable fibrils.

\section{CONCLUSIONS}

To conclude, we explored the potential of solvation effects to ellicit delicate control of peptide self-assembly into $1 \mathrm{D}$ and 2D nanostructures by using a library of cosolvents. Cosolvents with lower polarity (lower $E_{T}^{N}$ ) selectively interacted with alkyl and $\mathrm{Phe}_{6}$ segments of peptide amphiphiles. This resulted in volume exclusion effects and a weakening of the peptide association between hydrophobic walls, which then prevented $\beta$-sheet stacking. For the polar solvents, the aforementioned volume exclusion effects were more limited and the association of these hydrophobic walls was subsequently possible. We highlighted the complexity of the solvation effect in peptide self-assembly by demonstrated the existence of a kinetically trapped state. We anticipate this work can shed light on the design of peptide-based biomaterials and the modulation of protein structure and function (e.g., amyloid fibrillation, enzyme-substrate recognition, and protein-protein interaction).

\section{EXPERIMENTAL SECTION}

Reagents and Materials. All Fmoc-protected amino acids, Rink Amide resin, and 2-(1H-benzotriazol-1-yl)-1,1,3,3-tetramethyluronium hexafluorophosphate were purchased from Anaspec, Inc. The peptide $\mathrm{F} 6 \mathrm{C} 11$ was prepared according to our previous paper. ${ }^{45}$ All the other reagents were used as received.

Preparation of Peptide Nanostructures. A stock solution of 10 $\mathrm{mM}$ F6C11 was prepared in hexafluoro-2-propanol to completely break the hydrogen bonding between peptide molecules. Following Pathway I, $10 \mu \mathrm{L}$ of peptide stock solution was injected quickly into a $390 \mu \mathrm{L}$ solution containing phosphate buffer $(10 \mathrm{mM}, \mathrm{pH} 7)$ and desired amount of cosolvents. The mixture was sonicated for $20 \mathrm{~s}$ and stored at room temperature overnight. Following Pathway II, the preformed peptide nanosheets in phosphate buffer $(10 \mathrm{mM}, \mathrm{pH} 7)$ were mixed with desired amount of cosolvents. The mixture was sealed and stored at room temperature.

Transmission Electron Microscopy. TEM was performed on a JEM $2100 \mathrm{~F}$ with an acceleration voltage of $200 \mathrm{keV}$, and the images were recorded with an Orius camera. TEM samples were prepared using the negative-staining method. Briefly, a drop of solution was deposited onto a carbon-coated 200 mesh copper grid for $5 \mathrm{~min}$. Excess solution was wiped away using a filter paper. Subsequently, the grid was stained with a drop of uranyl acetate $(1.0 \mathrm{wt} \%)$ solution for 3 min. Excess staining agent was removed using a filter paper and the sample was dried in air. The calculation of $L / D$ of peptide nanosheets, nanobelts, and nanofibrils was performed using ImageJ.

Fluorescence Measurements. The ThT assay was performed in a 384-well plate with a total volume of $80 \mu \mathrm{L}$. The peptide solutions were incubated with $10 \mu \mathrm{M}$ ThT overnight before measurement. 
Fluorescence measurements were performed on a SpectraMax M5 plate reader with an excitation of $440 \mathrm{~nm}$.

Circular Dichroism. CD spectra were recorded using a Jasco-715 circular dichroism spectrophotometer at $20{ }^{\circ} \mathrm{C}$. The samples were loaded into a rectangular quartz cell with the light path length of 1 $\mathrm{mm}$. The peptide concentration was $0.25 \mathrm{mM}$ dissolved in phosphate buffer (10 mM, pH 7.0).

Structured Illumination Microscopy. Self-assembled peptide nanostructures were stained with Nile red $(5 \mu \mathrm{M})$ and diluted in phosphate buffer. The solution was absorbed on a positively charged microscope slide (SUPERFROST PLUS, Thermo Scientific) and mounted with $22 \mathrm{~mm}$ high-precision coverslips (Thermo Scientific) and sealed with clear nail varnish. SIM imaging was conducted on a Zeiss Elyra PS1 inverted microscope (Zeiss, Germany).

Atomic Force Microscopy. AFM was performed on an AFM 5500 microscope (Keysight technologies, previously Agilent). The measurements were performed in ambient atmosphere. A HQ:NSC15/Al BS tip ( $\mu$ masch) was used (tip radius $<8 \mathrm{~nm}$, force constant of $40 \mathrm{~N} / \mathrm{m}$, resonance frequency of $325 \mathrm{kHz}$ in tapping mode (measured resonance frequency $=274.432 \mathrm{kHz}$ ). AFM images were analyzed using Gwyddion 2.49.1. ${ }^{54}$ Prior to fiber measurements, data were processed by a level mean plate subtraction and rows were aligned using the median.

Model Construction. The initial model of the F6C11 molecule was constructed with all amino acid residues in the $\beta$-sheet arrangement and the connecting alkyl chain in an extended conformation. The $\mathrm{F} 6 \mathrm{C} 11_{10}$ fibrillar aggregate fragment was built by aligning 10 molecules with a space of $0.4 \mathrm{~nm}$ between adjacent molecules. The F6C11 and F6C11 10 structures were solvated with approximately 6000 water molecules and counterions and then equilibrated by MD simulation for $20 \mathrm{~ns}$ in the NPT (constant number of particles, pressure, and temperature) ensemble.

Water-alcohol mixtures were generated based on mass fractions equivalent to $5 \% \mathrm{v} / \mathrm{v}$ and subsequently equilibrated in the NPT ensemble. The mixtures contained between 176 and 399 alcohol molecules, depending on size, immersed in a $3 \mathrm{D}$ periodic box containing approximately 17000 water molecules. The pre-equilibrated single $\mathrm{F} 6 \mathrm{C} 11$ or $\mathrm{F} 6 \mathrm{C} 11_{10}$ fibril was then inserted into each of the equilibrated solvent mixtures. To remove unfavorable contacts, water or alcohol molecules overlaying the F6C11 molecules in systems were shifted, and the systems were equilibrated for $1 \mathrm{~ns}$ with the F6C11 atoms fixed. An all-atom representation of the F6C11 molecule and primary alcohol molecules was used with the intra- and intermolecular interactions being modeled by a combination of the CHARMM $36^{2,3}$ and CGenFF36 potentials. Water molecules were treated explicitly using the TIP3P water model. ${ }^{4}$

Simulation Setup. Molecular dynamics simulation as implemented in NAMD (version 2.10) s $^{5}$ software was used for all the work reported here. In all simulations, a cutoff distance of $12 \AA$ was applied for nonbonded interatomic interactions with switching applied between 10 and $12 \AA$. Long-range electrostatic interactions were treated using the particle mesh Ewald method. ${ }^{6}$ A time step size of 2 fs was used in all simulations, with $\mathrm{O}-\mathrm{H}$ bond lengths constrained using the SHAKE algorithm. ${ }^{7}$ NPT simulations were undertaken using a Langevin thermostat ${ }^{8}$ and Langevin piston Nose-Hoover method $^{9,10}$ to control the temperature and pressure at $298 \mathrm{~K}$ and 1 atm, respectively. Equilibration runs for the F6C11 molecule and fibrillar systems were performed for 220 and 120 ns, respectively, with an output frequency of $10 \mathrm{ps}$. Analysis was performed on the final 100 ns for each system using VMD. ${ }^{11}$

SASA Calculations. All SASA calculations were performed using the method developed by Connolly ${ }^{12}$ as implemented in VMD with a probe radius of $1.4 \AA$. For each frame the SASA of each region of the F6C11 molecule(s) was calculated by restricting the calculation to that region of the $\mathrm{F} 6 \mathrm{C} 11$ molecule(s) to give a $\mathrm{SASA}_{\mathrm{All}}$ for each region. A second calculation was performed with the selection including both the $\mathrm{F} 6 \mathrm{C} 11$ molecule(s) and organic solvent molecules within $5 \AA$ of the $\mathrm{F} 6 \mathrm{C} 11$ and applying the same restriction to give $\mathrm{SASA}_{(\mathrm{R} \text { OS })}$. The difference between $\mathrm{SASA}_{\mathrm{All}}$ and $\mathrm{SASA}_{\left(\mathrm{R} \_ \text {os }\right)}$ gives the total area of the region of the $\mathrm{F} 6 \mathrm{C} 11$ molecule(s) covered by organic solvent, $\mathrm{SASA}_{\mathrm{COV}}$. Dividing $\mathrm{SASA}_{\mathrm{COV}}$ by $\mathrm{SASA}_{\mathrm{All}}$ gives the fraction of the region of the $\mathrm{F} 6 \mathrm{C} 11$ molecule(s) covered by organic solvent. Distributions for SASA $_{\mathrm{COV}}$ are shown in Figures 4 and 5 and Figures S11-S13 and S15-S17.

\section{ASSOCIATED CONTENT}

Supporting Information

The Supporting Information is available free of charge on the ACS Publications website at DOI: 10.1021/acsnano.8b08117.

Experimental procedures, peptide synthesis, TEM images, AFM images, SIM images, and CD spectra (PDF)

\section{AUTHOR INFORMATION}

\section{Corresponding Authors}

*E-mail: irene.yarovsky@rmit.edu.au.

*E-mail: m.stevens@imperial.ac.uk.

ORCID

Yiyang Lin: 0000-0003-2017-190X

Michael R. Thomas: 0000-0001-7795-9648

Ye Wang: 0000-0002-0525-1832

E. Thomas Pashuck: 0000-0003-2881-4965

Irene Yarovsky: 0000-0002-4033-5150

Molly M. Stevens: 0000-0002-7335-266X

\section{Present Address}

${ }^{\S}$ Department of Bioengineering, Lehigh University, 111 Research Drive, D325, Bethlehem, PA 18015 USA.

\section{Notes}

The authors declare no competing financial interest.

\section{ACKNOWLEDGMENTS}

M.R.T. and M.M.S. acknowledge support from the Engineering and Physical Sciences Research Council (EPSRC) i-sense IRC in Early Warning Sensing Systems for Infectious Diseases [EP/ K031953/1]. J.P.W. and M.M.S. were funded by the grant from the U.K. Regenerative Medicine Platform "Acellular/ Smart Materials-3D Architecture" [MR/R015651/1]. Y.W. was supported by the China Scholarship Council. E.T.P. was supported by the ERC FP7Marie Curie actions through the Intra-European Marie Curie Fellowship "Peptide Osteogel" [275433]. I.Y. and M.M.S. acknowledge the Australian Research Council for financial support under the Discovery Project scheme [DP140101888 and DP170100511]. M.M.S. acknowledges the EPSRC grant "Bio-functionalized Nanomaterials for Ultra-sensitive Biosensing” [EP/K020641/1] and a Wellcome Trust Senior Investigator Award (098411/Z/12/Z). The authors acknowledge use of characterization facilities within the Harvey Flower Electron Microscopy Suite, Department of Materials, Imperial College London. Imaging was performed in the Facility for Imaging by Light Microscopy (FILM), partly supported by the Biotechnology and Biological Sciences Research Council (BBSRC) [BB/L015129/1]. This research was undertaken with the assistance of resources from the National Computational Infrastructure (NCI) [e87] and Melbourne Bioinformatics, Australia. Experimental raw data are available at DOI: 10.5281/zenodo.2543226. Molecular simulation data is available upon reasonable request from irene.yarovsky@rmit.edu.au. 


\section{REFERENCES}

(1) Aida, T.; Meijer, E. W.; Stupp, S. I. Functional Supramolecular Polymers. Science 2012, 335, 813-817.

(2) Wei, G.; Su, Z.; Reynolds, N. P.; Arosio, P.; Hamley, I. W.; Gazit, E.; Mezzenga, R. Self-Assembling Peptide and Protein Amyloids: From Structure to Tailored Function in Nanotechnology. Chem. Soc. Rev. 2017, 46, 4661-4708.

(3) Adler-Abramovich, L.; Gazit, E. The Physical Properties of Supramolecular Peptide Assemblies: From Building Block Association to Technological Applications. Chem. Soc. Rev. 2014, 43, 6881-6893.

(4) Fleming, S.; Ulijn, R. V. Design of Nanostructures Based on Aromatic Peptide Amphiphiles. Chem. Soc. Rev. 2014, 43, 8150-8177.

(5) Luo, Z.; Zhang, S. Designer Nanomaterials Using Chiral SelfAssembling Peptide Systems and Their Emerging Benefit for Society. Chem. Soc. Rev. 2012, 41, 4736-4754.

(6) Wang, J.; Liu, K.; Xing, R.; Yan, X. Peptide Self-Assembly: Thermodynamics and Kinetics. Chem. Soc. Rev. 2016, 45, 5589-5604.

(7) Adamcik, J.; Castelletto, V.; Bolisetty, S.; Hamley, I. W.; Mezzenga, R. Direct Observation of Time-Resolved Polymorphic States in the Self-Assembly of End-Capped Heptapeptides. Angew. Chem., Int. Ed. 2011, 50, 5495-5498.

(8) Nam, K. T.; Shelby, S. A.; Choi, P. H.; Marciel, A. B.; Chen, R.; Tan, L.; Chu, T. K.; Mesch, R. A.; Lee, B.-C.; Connolly, M. D.; Kisielowski, C.; Zuckermann, R. N. Free-Floating Ultrathin TwoDimensional Crystals from Sequence-Specific Peptoid Polymers. Nat. Mater. 2010, 9, 454-460.

(9) Baek, K.; Yun, G.; Kim, Y.; Kim, D.; Hota, R.; Hwang, I.; Xu, D.; Ko, Y. H.; Gu, G. H.; Suh, J. H.; Park, C. G.; Sung, B. J.; Kim, K. FreeStanding, Single-Monomer-Thick Two-Dimensional Polymers through Covalent Self-Assembly in Solution. J. Am. Chem. Soc. 2013, 135, 6523-6528.

(10) Heuser, T.; Weyandt, E.; Walther, A. Biocatalytic FeedbackDriven Temporal Programming of Self-Regulating Peptide Hydrogels. Angew. Chem., Int. Ed. 2015, 54, 13258-13262.

(11) Miao, X.; Cao, W.; Zheng, W.; Wang, J.; Zhang, X.; Gao, J.; Yang, C.; Kong, D.; Xu, H.; Wang, L.; Yang, Z. Switchable Catalytic Activity: Selenium-Containing Peptides with Redox-Controllable SelfAssembly Properties. Angew. Chem., Int. Ed. 2013, 52, 7781-7785.

(12) Rybtchinski, B. Adaptive Supramolecular Nanomaterials Based on Strong Noncovalent Interactions. ACS Nano 2011, 5, 6791-6818.

(13) Mason, T. O.; Michaels, T. C. T.; Levin, A.; Dobson, C. M.; Gazit, E.; Knowles, T. P. J.; Buell, A. K. Thermodynamics of Polypeptide Supramolecular Assembly in the Short-Chain Limit. J. Am. Chem. Soc. 2017, 139, 16134-16142.

(14) Aggeli, A.; Bell, M.; Carrick, L. M.; Fishwick, C. W. G.; Harding, R.; Mawer, P. J.; Radford, S. E.; Strong, A. E.; Boden, N. Ph as a Trigger of Peptide $\beta$-Sheet Self-Assembly and Reversible Switching between Nematic and Isotropic Phases. J. Am. Chem. Soc. 2003, 125, 9619-9628.

(15) Muraoka, T.; Koh, C.-Y.; Cui, H.; Stupp, S. I. Light-Triggered Bioactivity in Three Dimensions. Angew. Chem., Int. Ed. 2009, 48, 5946-5949.

(16) Zou, R.; Wang, Q.; Wu, J.; Wu, J.; Schmuck, C.; Tian, H. Peptide Self-Assembly Triggered by Metal Ions. Chem. Soc. Rev. 2015, $44,5200-5219$

(17) Toledano, S.; Williams, R. J.; Jayawarna, V.; Ulijn, R. V. Enzyme-Triggered Self-Assembly of Peptide Hydrogels via Reversed Hydrolysis. J. Am. Chem. Soc. 2006, 128, 1070-1071.

(18) Yang, Z.; Gu, H.; Fu, D.; Gao, P.; Lam, J. K.; Xu, B. Enzymatic Formation of Supramolecular Hydrogels. Adv. Mater. 2004, 16, $1440-1444$.

(19) Hirst, A. R.; Roy, S.; Arora, M.; Das, A. K.; Hodson, N.; Murray, P.; Marshall, S.; Javid, N.; Sefcik, J.; Boekhoven, J.; van Esch, J. H.; Santabarbara, S.; Hunt, N. T.; Ulijn, R. V. Biocatalytic Induction of Supramolecular Order. Nat. Chem. 2010, 2, 1089-1094.

(20) Feng, Z.; Wang, H.; Chen, X.; Xu, B. Self-Assembling Ability Determines the Activity of Enzyme-Instructed Self-Assembly for Inhibiting Cancer Cells. J. Am. Chem. Soc. 2017, 139, 15377-15384.
(21) Kim, J. R.; Muresan, A.; Lee, K. Y. C.; Murphy, R. M. Urea Modulation of $\beta$-Amyloid Fibril Growth: Experimental Studies and Kinetic Models. Protein Sci. 2004, 13, 2888-2898.

(22) Medrano, M.; Fuertes, M. Á.; Valbuena, A.; Carrillo, P. J. P.; Rodríguez-Huete, A.; Mateu, M. G. Imaging and Quantitation of a Succession of Transient Intermediates Reveal the Reversible SelfAssembly Pathway of a Simple Icosahedral Virus Capsid. J. Am. Chem. Soc. 2016, 138, 15385-15396.

(23) Sorrenti, A.; Leira-Iglesias, J.; Markvoort, A. J.; de Greef, T. F. A.; Hermans, T. M. Non-Equilibrium Supramolecular Polymerization. Chem. Soc. Rev. 2017, 46, 5476-5490.

(24) Korevaar, P. A.; Newcomb, C. J.; Meijer, E. W.; Stupp, S. I. Pathway Selection in Peptide Amphiphile Assembly. J. Am. Chem. Soc. 2014, 136, 8540-8543.

(25) Görl, D.; Zhang, X.; Stepanenko, V.; Würthner, F. Supramolecular Block Copolymers by Kinetically Controlled Co-SelfAssembly of Planar and Core-Twisted Perylene Bisimides. Nat. Commun. 2015, 6, 7009.

(26) Ogi, S.; Fukui, T.; Jue, M. L.; Takeuchi, M.; Sugiyasu, K. Kinetic Control over Pathway Complexity in Supramolecular Polymerization through Modulating the Energy Landscape by Rational Molecular Design. Angew. Chem., Int. Ed. 2014, 53, 14363-14367.

(27) Wang, G.; Tang, B.; Liu, Y.; Gao, Q.; Wang, Z.; Zhang, X. The Fabrication of a Supra-Amphiphile for Dissipative Self-Assembly. Chem. Sci. 2016, 7, 1151-1155.

(28) Spitzer, D.; Rodrigues, L. L.; Straßburger, D.; Mezger, M.; Besenius, P. Tuneable Transient Thermogels Mediated by a $\mathrm{pH}-$ and Redox-Regulated Supramolecular Polymerization. Angew. Chem., Int. Ed. 2017, 56, 15461-15465.

(29) Tidhar, Y.; Weissman, H.; Wolf, S. G.; Gulino, A.; Rybtchinski, B. Pathway-Dependent Self-Assembly of Perylene Diimide/Peptide Conjugates in Aqueous Medium. Chem. - Eur. J. 2011, 17, 60686075.

(30) Endo, M.; Fukui, T.; Jung, S. H.; Yagai, S.; Takeuchi, M.; Sugiyasu, K. Photoregulated Living Supramolecular Polymerization Established by Combining Energy Landscapes of Photoisomerization and Nucleation-Elongation Processes. J. Am. Chem. Soc. 2016, 138, 14347-14353.

(31) Fukui, T.; Kawai, S.; Fujinuma, S.; Matsushita, Y.; Yasuda, T.; Sakurai, T.; Seki, S.; Takeuchi, M.; Sugiyasu, K. Control over Differentiation of a Metastable Supramolecular Assembly in One and Two Dimensions. Nat. Chem. 2016, 9, 493-499.

(32) Xing, P.; Li, P.; Chen, H.; Hao, A.; Zhao, Y. Understanding Pathway Complexity of Organic Micro/Nanofiber Growth in Hydrogen-Bonded Coassembly of Aromatic Amino Acids. ACS Nano 2017, 11, 4206-4216.

(33) Korevaar, P. A.; de Greef, T. F. A.; Meijer, E. W. Pathway Complexity in $\pi$-Conjugated Materials. Chem. Mater. 2014, 26, 576586.

(34) Korevaar, P. A.; George, S. J.; Markvoort, A. J.; Smulders, M. M. J.; Hilbers, P. A. J.; Schenning, A. P. H. J.; De Greef, T. F. A.; Meijer, E. W. Pathway Complexity in Supramolecular Polymerization. Nature 2012, 481, 492-496.

(35) Ishiba, K.; Noguchi, T.; Iguchi, H.; Morikawa, M. a.; Kaneko, K.; Kimizuka, N. Photoresponsive Nanosheets of Polyoxometalates Formed by Controlled Self-Assembly Pathways. Angew. Chem., Int. Ed. 2017, 56, 2974-2978.

(36) Aliprandi, A.; Mauro, M.; De Cola, L. Controlling and Imaging Biomimetic Self-Assembly. Nat. Chem. 2016, 8, 10-15.

(37) Arnon, Z. A.; Vitalis, A.; Levin, A.; Michaels, T. C. T.; Caflisch, A.; Knowles, T. P. J.; Adler-Abramovich, L.; Gazit, E. Dynamic Microfluidic Control of Supramolecular Peptide Self-Assembly. Nat. Commun. 2016, 7, 13190.

(38) Gunsteren, W. F. V.; Luque, F. J.; Timms, D.; Torda, A. E. Molecular Mechanics in Biology: From Structure to Function, Taking Account of Solvation. Annu. Rev. Biophys. Biomol. Struct. 1994, 23, 847-863. 
(39) Grudzielanek, S.; Jansen, R.; Winter, R. Solvational Tuning of the Unfolding, Aggregation and Amyloidogenesis of Insulin. J. Mol. Biol. 2005, 351, 879-894.

(40) Cui, H.; Chen, Z.; Zhong, S.; Wooley, K. L.; Pochan, D. J. Block Copolymer Assembly via Kinetic Control. Science 2007, 317, 647-650.

(41) Pochan, D. J.; Chen, Z.; Cui, H.; Hales, K.; Qi, K.; Wooley, K. L. Toroidal Triblock Copolymer Assemblies. Science 2004, 306, 9497.

(42) Shen, C. L.; Murphy, R. M. Solvent Effects on Self-Assembly of $\beta$-Amyloid Peptide. Biophys. J. 1995, 69, 640-651.

(43) Wang, J.; Liu, K.; Yan, L.; Wang, A.; Bai, S.; Yan, X. Trace Solvent as a Predominant Factor to Tune Dipeptide Self-Assembly. ACS Nano 2016, 10, 2138-2143.

(44) Zhang, L.; Eisenberg, A. Multiple Morphologies of "Crew-Cut" Aggregates of Polystyrene- $b$-Poly(Acrylic Acid) Block Copolymers. Science 1995, 268, 1728-1731.

(45) Lin, Y.; Thomas, M. R.; Gelmi, A.; Leonardo, V.; Pashuck, E. T.; Maynard, S. A.; Wang, Y.; Stevens, M. M. Self-Assembled 2D Free-Standing Janus Nanosheets with Single-Layer Thickness. J. Am. Chem. Soc. 2017, 139, 13592-13595.

(46) Cui, H.; Muraoka, T.; Cheetham, A. G.; Stupp, S. I. SelfAssembly of Giant Peptide Nanobelts. Nano Lett. 2009, 9, 945-951.

(47) Cui, H.; Cheetham, A. G.; Pashuck, E. T.; Stupp, S. I. Amino Acid Sequence in Constitutionally Isomeric Tetrapeptide Amphiphiles Dictates Architecture of One-Dimensional Nanostructures. J. Am. Chem. Soc. 2014, 136, 12461-12468.

(48) Hu, Y.; Lin, R.; Zhang, P.; Fern, J.; Cheetham, A. G.; Patel, K.; Schulman, R.; Kan, C.; Cui, H. Electrostatic-Driven Lamination and Untwisting of $\beta$-Sheet Assemblies. ACS Nano 2016, 10, 880-888.

(49) Bowerman, C. J.; Liyanage, W.; Federation, A. J.; Nilsson, B. L. Tuning $\beta$-Sheet Peptide Self-Assembly and Hydrogelation Behavior by Modification of Sequence Hydrophobicity and Aromaticity. Biomacromolecules 2011, 12, 2735-2745.

(50) Lin, Y.; Pashuck, E. T.; Thomas, M. R.; Amdursky, N.; Wang, S.-T.; Chow, L. W.; Stevens, M. M. Plasmonic Chirality Imprinting on Nucleobase-Displaying Supramolecular Nanohelices by Metal-Nucleobase Recognition. Angew. Chem., Int. Ed. 2017, 56, 2361-2365.

(51) Reichardt, C.; Welton, T. Solvents and Solvent Effects in Organic Chemistry; Wiley-VCH Verlag GmbH \& Co. KGaA: Weinheim, Germany, 2010; p 425-508.

(52) Maryott, A. A.; Smith, E. R. Table of Dielectric Constants of Pure Liquids; U.S. Govt. Print Office, Washington, DC, 1951.

(53) Ma, X.; Zhang, S.; Jiao, F.; Newcomb, C. J.; Zhang, Y.; Prakash, A.; Liao, Z.; Baer, M. D.; Mundy, C. J.; Pfaendtner, J.; Noy, A.; Chen, C.-L.; De Yoreo, J. J. Tuning Crystallization Pathways through Sequence Engineering of Biomimetic Polymers. Nat. Mater. 2017, 16, $767-774$.

(54) Nečas, D.; Klapetek, P. Gwyddion: An Open-Source Software for Spm Data Analysis. Cent. Eur. J. Phys. 2012, 10, 181-188. 